\title{
Variability of Multiple Sclerosis Spasticity Symptoms in Response to THC:CBD Oromucosal Spray: Tracking Cases through Clinical Scales and Video Recordings
}

\author{
Peter Flachenecker ${ }^{a} \quad$ Francesco Saccà $^{b} \quad$ Carlos Vila $^{c}$ \\ aNeurological Rehabilitation Center Quellenhof, Bad Wildbad, Germany; ${ }^{b}$ Department of \\ Neurosciences, Reproductive and Odontostomatological Sciences, University of Naples \\ Federico II, Naples, Italy; 'Global Medical Affairs, Almirall S.A., Barcelona, Spain
}

\section{Keywords}

Multiple sclerosis spasticity $\cdot$ THC:CBD oromucosal spray $\cdot$ Symptom variability

\begin{abstract}
Multiple sclerosis (MS) is an inflammatory and neurodegenerative autoimmune demyelinating disease of the central nervous system. Patients exhibit heterogeneous patterns of disabling symptoms, including spasticity. In the majority of patients with MS spasticity, it and its associated symptoms contribute to disability, interfere with performance of everyday activities, and impair quality of life. Even under treatment with oral antispasticity drugs, about a third of patients continue to experience spasticity of moderate to severe intensity, underscoring the need for additional treatment options. The efficacy of tetrahydrocannabinol:cannabidiol (THC:CBD) oromucosal spray as add-on therapy in patients with refractory MS spasticity has been demonstrated in clinical trials and observational studies. To gain insight into patients' response to treatment at the individual level, in-depth changes from baseline in various clinical scales and
\end{abstract}




\section{Case Reports in Neurology}

video-assessed parameters were evaluated in patients with resistant MS spasticity before and after 1 month of treatment with THC:CBD oromucosal spray. All 6 patients showed $\geq 20 \% \mathrm{im}$ provement in the spasticity Numerical Rating Scale (i.e., were initial responders to treatment), but displayed individual variability in other spasticity-related parameters. Improved Modified Ashworth Scale scores were observed in 5 cases, with a reduction of $-2 /-3$ points in lower limb scores for 1 patient who also showed benefit in terms of a more stable gait but modest improvement in the timed 10-meter walk test (10MWT). Improvement in the 10MWT (or 25-foot walk test) was noted in 4 of the 6 cases. THC:CBD oromucosal spray also improved upper limb function as indicated by faster 9 -Hole Peg Test results.

(C) 2018 The Author(s)

Published by S. Karger AG, Basel

\section{Introduction}

Multiple sclerosis (MS) is an inflammatory and neurodegenerative autoimmune demyelinating disease of the central nervous system with a varied and unpredictable course [1]. Disability domains include mobility, spasticity, pain, manual dexterity, sensory, tremor/coordination, bowel/bladder function, fatigue, and cognitive function [2]. The severity of impairment increases as the disease progresses, although the patterns of disabling symptoms can vary widely among individuals [2].

Patients with MS spasticity have greater overall disability compared to patients without spasticity, with restricted mobility being commonly reported [3]. As severity worsens, MS spasticity (spasms, muscle rigidity) and its associated symptoms place an increasingly greater demand on healthcare resources [3] and have an increasingly greater negative impact on patients' quality of life $[4,5]$.

First-line treatment options for MS spasticity include oral antispasticity drugs such as baclofen and tizanidine, often associated with drugs such as gabapentin, pregabalin, and antidepressants [6]. Despite pharmacological treatment, around a third of patients with MS spasticity continue to experience symptoms of moderate to severe intensity, highlighting a considerable unmet need [2, 7]. Tetrahydrocannabinol:cannabidiol (THC:CBD) oromucosal spray (Sativex ${ }^{\circledR}$, USAN name: nabiximols) is indicated as add-on therapy in patients who show nonresponsiveness or develop tolerance to first-line antispasticity agents [8]. The efficacy of THC:CBD oromucosal spray for symptomatic relief of MS spasticity has been demonstrated in large phase 3 clinical trials $[9,10]$ and in routine clinical practice $[11,12]$. THC:CBD oromucosal spray has also shown a trend towards improving objective measures of spasticity such as the timed 10-meter walk test (10MWT) $[9,10]$.

To gain insight into patients' response to THC:CBD oromucosal spray at the individual level, in-depth MS spasticity signs were assessed in patients with moderate or severe resistant MS spasticity before and after 1 month of treatment with THC:CBD oromucosal spray as per its approved label [8]. 


\section{Case Reports in Neurology}

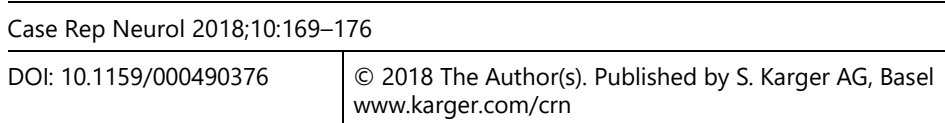

Flachenecker et al.: Variability of Multiple Sclerosis Spasticity Symptoms in Response to THC:CBD Oromucosal Spray

Methods

Inclusion criteria for the study were MS spasticity patients aged $\geq 18$ years who fulfilled approved label criteria for use of THC:CBD oromucosal spray [8], including a positive response ( $\geq 20 \%$ improvement from baseline on the spasticity 0-10 Numerical Rating Scale [NRS]) to THC:CBD spray after a 1-month trial period (i.e., initial responders). Baseline videos for nonresponders to THC:CBD spray were discarded. Each participating patient provided signed informed consent.

MS spasticity signs were assessed at a baseline visit and after a 1-month trial period of treatment with THC:CBD oromucosal spray. Data recorded for patients at each visit comprised tests and videos for at least 2 mobility situations and 2 rigidity situations. Videos were taken with a photographic, video, smartphone, or tablet camera mounted on a tripod. The minimal required recording quality was $\mathrm{HD}(1,920 \times 1,080$ pixels $)$ at 25 frames per second. Analyses included the spasticity 0-10 NRS, pain 0-10 NRS, Expanded Disability Status Scale (EDSS), Modified Ashworth Scale (MAS) [13], Timed Up and Go (TUG) test, 9-Hole Peg Test (9-HPT) [14], grab an object task, gait assessment, and physiotherapy/rehabilitation. In accordance with requirements of the respective regulatory agencies, patients also performed the 10MWT [14] in Italy or the 25-foot walk test (T25-FW) in Germany.

\section{Results}

Six patients were enrolled between March 1, and June 30,2016, at a single center each in Germany $(n=3)$ and Italy $(n=3)$. Their clinical characteristics are summarized in Table 1 . The patients ( 2 male and 4 female) ranged in age from 33 to 65 years, and time since diagnosis ranged from 15 to 42 years. Four patients had relapsing-remitting MS (RRMS), 1 had progressive relapsing MS, and 1 had secondary progressive MS (SPMS). Baseline EDSS scores (range: 2.0-7.0) indicated a wide range of disability levels. Baclofen was the primary medication in 5 patients (Cases 1-5), and gabapentin plus fampridine in the remaining patient (Case 6).

Changes in clinical scales after 1 month of add-on therapy with THC:CBD oromucosal spray are shown in Table 2. THC:CBD oromucosal spray reduced MS spasticity severity in all patients, as indicated by 20-56\% improvement from baseline in spasticity 0-10 NRS scores. Reductions of $25 \%$ in 3 patients and up to $50 \%$ in a fourth patient were recorded on the pain 0-10 NRS (Cases 1-4). The EDSS remained unchanged in 3 patients (Cases 1-3) and was reduced by -0.5 points in Cases 4-6. Improvement on the MAS was observed in 5 of the 6 patients, with the most marked change being a decrease of $-2 /-3$ points in lower limb scores in Case 2. The 10MWT/T25-FW was improved in 4 patients (time reduced by $6-17 \%$ ), but not in the remaining 2 patients (time increased by 8 and 21\%, respectively).

With regard to video-assessed parameters (Table 3), THC:CBD oromucosal spray improved results for the 9-HPT using either hand in 2 patients (Cases 2 and 3), whereas a third patient (Case 1) showed improvement only in the nondominant hand. Video analysis indicated increased gait velocity or improved gait stability in patients who had shown the most marked improvement in the 10MWT/T25-FW (Cases 2, 4, and 5). Increased knee flexibility was observed in Case 4. Video analysis identified a faster, easier TUG, and a more stable gait in Case 2, in addition to marked improvement in the spasticity NRS, pain NRS, and 


\section{Case Reports in Neurology}

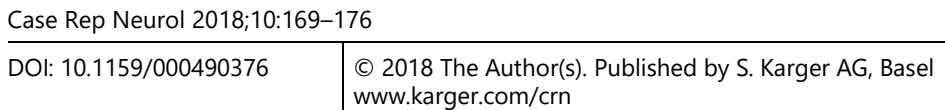

Flachenecker et al.: Variability of Multiple Sclerosis Spasticity Symptoms in Response to THC:CBD Oromucosal Spray

MAS. A faster and easier TUG was observed in Case 4, with a better result for "stand up from lying and go" after treatment.

\section{Discussion}

All 6 patients described in this case series showed improvement from baseline of $\geq 20 \%$ on the spasticity 0-10 NRS after 1 month of add-on treatment with THC:CBD oromucosal spray, thus qualifying as early treatment responders. This trial of therapy approach to identify treatment responders was first applied in the enriched-study phase 3 clinical trial of THC:CBD oromucosal spray versus placebo in patients with treatment-resistant MS spasticity [10]. After single-blind treatment with THC:CBD spray for 1 month, approximately half of enrolled patients (47.5\%) were early responders ( $\geq 20 \%$ NRS improvement). During the 12 -week double-blind treatment phase, significantly more of the early responders randomized to THC:CBD oromucosal spray than placebo achieved clinically relevant reductions in MS spasticity and associated symptoms such as spasm frequency and sleep disturbances. An observational study in everyday clinical practice reported symptomatic relief of resistant MS spasticity as judged by investigators in $74.6 \%$ of patients $(206 / 276)$ after 1 month of treatment with THC:CBD oromucosal spray [11]. Associated improvements in spasticity-related symptoms and patients' ability to perform daily activities corresponded with the level of response $(\geq 20 \%$ or $\geq 30 \%$ NRS improvement thresholds). The trial of therapy approach is a useful method of identifying, and limiting exposure of an intervention to, patients who are most likely to benefit from treatment.

Although improvement in the spasticity 0-10 NRS was a consistent finding in each of the six patients, changes in other clinical scales and video-assessed parameters were more varied. Improvement in MAS scores occurred in five cases and was supported by video evidence. The most marked improvement was a reduction of $-2 /-3$ points in lower limb scores, as described in Case 2. This patient also had a more stable gait identified by video analysis and a modest improvement $(-10 \%)$ in the 10MWT. The 2 cases with the largest improvement in the T25FW test (Cases 4 and 5 ) also had increased gait velocity confirmed by video analysis. On the other hand, 1 patient (Case 6) had a prolonged T25-FW test $(+21 \%)$ despite having shown $50 \%$ improvement on the spasticity NRS and improvement of 0.5 points on the EDSS.

THC:CBD oromucosal spray also improved upper limb function as indicated by better results for the 9HPT in all 3 patients who performed the test (Cases 1-3), although only 1 patient (Case 2) showed improvement in the grab an object task. This finding suggests that the spasticity 0-10 NRS alone may not be sufficiently informative of the individual benefits patients may gain during treatment with THC:CBD oromucosal spray. An extensive examination, with functional tests, could provide a qualitative analysis that may guide clinical decisions such as dose adjustments and daily fractionations of the drug. This, in turn, may prove to be informative in patients who show a suboptimal response on the NRS, but have evidence of some functional improvement.

The study is limited by the small patient sample and relatively short period of observation, which limit the ability to draw conclusions. Due to the length of time required to perform/undergo such an extended battery of tests, patient and investigator recruitment proved to be a challenge. Nevertheless, it was interesting to observe that these 6 patients with a long- 
standing history of MS and moderate to severe resistant MS spasticity at baseline responded to add-on treatment with THC:CBD oromucosal spray. Although changes from baseline in various parameters of MS spasticity varied widely among the participating patients, this is not unexpected given the highly individualized natural history of MS and of MS spasticity. Importantly, during the treatment phase when titration to the most effective dose of THC:CBD oromucosal spray was in progress, each patient experienced improvement in at least 1 spasticity-associated parameter. These preliminary results suggest that extending the study to a larger group of patients over a longer period of time (e.g., 3 months) might provide useful information about the broad range of benefits patients taking THC:CBD oromucosal spray can experience in addition to a decrease in MS spasticity severity as measured by the NRS or MAS.

\section{Conclusions}

In summary, the results of this case series show that THC:CBD oromucosal spray used as add-on therapy to conventional antispasticity agents consistently improved spasticity severity as measured with the spasticity 0-10 NRS, and had variable effects on other MS spasticityrelated parameters. The range of benefits patients with MS spasticity may experience during treatment with THC:CBD oromucosal spray are highly individualized and are seemingly not fully captured by the spasticity 0-10 NRS alone.

The study outcome supports a recommendation to specialists to explore and ask patients in more detail about the evolution in their MS spasticity-related impairment, and not just monitor changes on spasticity scales (NRS, Ashworth, etc.). This approach will lead to better capture of spasticity evolution and ultimately help optimize treatment decisions and responses.

\section{Acknowledgement}

Writing assistance was provided by Content Ed Net (Madrid, Spain), with funding from Almirall S.A. (Barcelona, Spain).

\section{Statement of Ethics}

The study received ethical approval from local independent Ethics Committees. All subjects provided their written, informed consent.

\section{Disclosure Statement}

P.F. has received speaker's fees and honoraria for advisory boards from Almirall, Bayer, Biogen Idec, Genzyme, Novartis, Merck-Serono, Sanofi, Roche, and Teva. None resulted in a conflict of interest. 
F.S. received personal compensation for public speaking, editorial work, and advisory boards from Almirall, Biogen Idec, Forward Pharma, Merck-Serono, Novartis, Pomona, Roche, Sanofi-Genzyme, and Teva.

C.V. is a full-time employee of Almirall S.A.

\section{References}

1 Frohman EM, Racke MK, Raine CS. Multiple sclerosis-the plaque and its pathogenesis. N Engl J Med. 2006 Mar;354(9):942-55.

2 Kister I, Bacon TE, Chamot E, Salter AR, Cutter GR, Kalina JT, et al. Natural history of multiple sclerosis symptoms. Int J MS Care. 2013;15(3):146-58.

3 Oreja-Guevara C, González-Segura D, Vila C. Spasticity in multiple sclerosis: results of a patient survey. Int J Neurosci. 2013 Jun;123(6):400-8.

4 Zwibel HL. Contribution of impaired mobility and general symptoms to the burden of multiple sclerosis. Adv Ther. 2009 Dec;26(12):1043-57.

5 Flachenecker P, Henze T, Zettl UK. Spasticity in patients with multiple sclerosis - clinical characteristics, treatment and quality of life. Acta Neurol Scand. 2014 Mar;129(3):154-62.

6 Otero-Romero S, Sastre-Garriga J, Comi G, Hartung HP, Soelberg Sørensen P, Thompson AJ, et al. Pharmacological management of spasticity in multiple sclerosis: systematic review and consensus paper. Mult Scler. 2016 Oct;22(11):1386-96.

$7 \quad$ Pozzilli C. Advances in the management of multiple sclerosis spasticity: experiences from recent studies and everyday clinical practice. Expert Rev Neurother. 2013 Dec;13(12 Suppl):49-54.

8 eMC. Sativex Oromucosal Spray SPC; 2015. https://www.medicines.org.uk/emc/medicine/23262

9 Collin C, Ehler E, Waberzinek G, Alsindi Z, Davies P, Powell K, et al. A double-blind, randomized, placebocontrolled, parallel-group study of Sativex, in subjects with symptoms of spasticity due to multiple sclerosis. Neurol Res. 2010 Jun;32(5):451-9.

10 Novotna A, Mares J, Ratcliffe S, Novakova I, Vachova M, Zapletalova O, et al.; Sativex Spasticity Study Group. A randomized, double-blind, placebo-controlled, parallel-group, enriched-design study of nabiximols* (Sativex $(\circledR)$ ), as add-on therapy, in subjects with refractory spasticity caused by multiple sclerosis. Eur J Neurol. 2011 Sep;18(9):1122-31.

11 Flachenecker P, Henze T, Zettl UK. Nabiximols (THC/CBD oromucosal spray, Sativex ${ }^{\circledR}$ ) in clinical practiceresults of a multicenter, non-interventional study (MOVE 2) in patients with multiple sclerosis spasticity. Eur Neurol. 2014;71(5-6):271-9.

12 Patti F, Messina S, Solaro C, Amato MP, Bergamaschi R, Bonavita S, et al.; SA.FE. study group. Efficacy and safety of cannabinoid oromucosal spray for multiple sclerosis spasticity. J Neurol Neurosurg Psychiatry. 2016 Sep;87(9):944-51.

13 Bohannon RW, Smith MB. Interrater reliability of a modified Ashworth scale of muscle spasticity. Phys Ther. 1987 Feb;67(2):206-7.

14 Cutter GR, Baier ML, Rudick RA, Cookfair DL, Fischer JS, Petkau J, et al. Development of a multiple sclerosis functional composite as a clinical trial outcome measure. Brain. 1999 May;122(Pt 5):871-82. 
Table 1. Clinical characteristics of MS spasticity patients: Cases 1-6

\begin{tabular}{|c|c|c|c|c|c|c|}
\hline Parameter & Case 1 & Case 2 & Case 3 & Case 4 & Case 5 & Case 6 \\
\hline Gender & female & female & male & female & female & male \\
\hline Age, years & 45 & 65 & 33 & 51 & 58 & 52 \\
\hline Age at diagnosis, years & 18 & 37 & 18 & 16 & 16 & 20 \\
\hline Time since diagnosis, years & 27 & 28 & 15 & 35 & 42 & 32 \\
\hline $\begin{array}{l}\text { MS type } \\
\text { Expanded Disability }\end{array}$ & RRMS & RRMS & RRMS & RRMS & PRMS & SPMS \\
\hline $\begin{array}{l}\text { Status Scale }(0-10) \\
\text { Primary medication }\end{array}$ & $\begin{array}{l}3.0 \\
\text { baclofen } \\
(25 \mathrm{mg} / \\
\text { day) }\end{array}$ & $\begin{array}{l}5.5 \\
\text { baclofen } \\
\text { (50 mg/ } \\
\text { day) }\end{array}$ & $\begin{array}{l}2.0 \\
\text { baclofen } \\
(25 \mathrm{mg} / \\
\text { day) }\end{array}$ & $\begin{array}{l}6.0 \\
\text { baclofen } \\
(60 \mathrm{mg} / \\
\text { day) }\end{array}$ & $\begin{array}{l}7.0 \\
\text { baclofen } \\
(20 \mathrm{mg} / \\
\text { day) }\end{array}$ & $\begin{array}{l}7.0 \\
\text { gabapentin } \\
(300 \mathrm{mg} / \\
\text { day })+ \\
\text { fampridine }\end{array}$ \\
\hline
\end{tabular}

MS, multiple sclerosis; PRMS, progressive relapsing multiple sclerosis; RRMS, relapsing-remitting multiple sclerosis; SPMS, secondary progressive multiple sclerosis.

Table 2. Change from baseline in clinical scales in patients with multiple sclerosis spasticity after 1 month of add-on therapy with THC:CBD oromucosal spray

\begin{tabular}{|c|c|c|c|c|c|c|}
\hline Parameter & Case 1 & Case 2 & Case 3 & Case 4 & Case 5 & Case 6 \\
\hline \multicolumn{7}{|l|}{ Clinical scales } \\
\hline Spasticity 0-10 NRS & $\begin{array}{l}-25 \% \text { morning; } \\
-25 \% \text { afternoon }\end{array}$ & $\begin{array}{l}-25 \% \text { morning; } \\
-25 \% \text { afternoon }\end{array}$ & $\begin{array}{l}-25 \% \text { morning; } \\
-25 \% \text { afternoon }\end{array}$ & $\begin{array}{l}-56 \% \text { to }-30 \% \\
\text { (noon) }\end{array}$ & $-20 \%$ & $-50 \%$ \\
\hline Pain 0-10 NRS & $\begin{array}{l}-25 \% \text { morning; } \\
0 \% \text { afternoon }\end{array}$ & $\begin{array}{l}-25 \% \text { morning; } \\
-25 \% \text { afternoon }\end{array}$ & $\begin{array}{l}-25 \% \text { morning; } \\
-25 \% \text { afternoon }\end{array}$ & $\begin{array}{l}-50 \% \text { to }-25 \% \\
\text { (noon) }\end{array}$ & no change & no change \\
\hline $\begin{array}{l}\text { Expanded } \\
\text { Disability } \\
\text { Status Scale }\end{array}$ & no change & no change & no change & -0.5 & -0.5 & -0.5 \\
\hline $\begin{array}{l}\text { Modified Ashworth } \\
\text { Scale }\end{array}$ & -1 & $\begin{array}{l}-2 /-3 \text { in lower } \\
\text { limbs }\end{array}$ & -1 & -1 & -1 & no change \\
\hline $\begin{array}{l}10 \text { MWT (Italy) } \\
\text { or T25-FW } \\
\text { (Germany) }\end{array}$ & $-6 \%$ & $-10 \%$ & $+8 \%$ & $-16 \%$ & $-17 \%$ & $+21 \%$ \\
\hline $\begin{array}{l}\text { Walking } \\
\text { distance }\end{array}$ & $\begin{array}{l}\text { no change: fully } \\
\text { ambulatory } \\
(>1,000 \mathrm{~m})\end{array}$ & $\begin{array}{l}\text { no change } \\
(180 \mathrm{~m})\end{array}$ & $\begin{array}{l}\text { no change: fully } \\
\text { ambulatory } \\
(>1,000 \mathrm{~m})\end{array}$ & $\begin{array}{l}\text { from } 100 \mathrm{~m} \text { with } \\
\text { cane to } 100 \mathrm{~m} \\
\text { without cane/ } \\
800 \mathrm{~m} \text { with cane }\end{array}$ & $\begin{array}{l}\text { using a } \\
\text { rollator: } \\
\text { from 5-10 } \\
\text { to } 25-50 \mathrm{~m}\end{array}$ & $\begin{array}{l}\text { using a } \\
\text { rollator: from } \\
8 \text { to } 20 \mathrm{~m}\end{array}$ \\
\hline Miscellaneous & & & & $\begin{array}{l}\text { awakening due to } \\
\text { night spasms } \\
\text { eradicated }\end{array}$ & & \\
\hline
\end{tabular}

NRS, Numerical Rating Scale; 10MWT, timed 10-meter walk test; T25-FW, timed 25-foot walk test. 
Flachenecker et al.: Variability of Multiple Sclerosis Spasticity Symptoms in Response to THC:CBD Oromucosal Spray

Table 3. Change from baseline in video-assessed parameters in patients with multiple sclerosis spasticity after 1 month of add-on therapy with THC:CBD oromucosal spray

\begin{tabular}{|c|c|c|c|c|c|c|}
\hline Parameter & Case 1 & Case 2 & Case 3 & Case 4 & Case 5 & Case 6 \\
\hline $\begin{array}{l}\text { Video assessment } \\
\text { Dominant 9-HPT }\end{array}$ & no change & faster & faster & $\begin{array}{l}\text { not } \\
\text { performed }\end{array}$ & $\begin{array}{l}\text { not } \\
\text { performed }\end{array}$ & $\begin{array}{l}\text { not } \\
\text { performed }\end{array}$ \\
\hline Nondominant 9-HPT & faster & faster & faster & $\begin{array}{l}\text { not } \\
\text { performed }\end{array}$ & $\begin{array}{l}\text { not } \\
\text { performed }\end{array}$ & $\begin{array}{l}\text { not } \\
\text { performed }\end{array}$ \\
\hline TUG & no change & $\begin{array}{l}\text { faster and } \\
\text { easier; gait } \\
\text { more stable }\end{array}$ & no change & $\begin{array}{l}\text { faster and } \\
\text { easier }\end{array}$ & no change & $\begin{array}{l}\text { not } \\
\text { performed }\end{array}$ \\
\hline GUG & no data & no data & no data & $\begin{array}{l}\text { stand up from } \\
\text { lying and go: } \\
\text { easier }\end{array}$ & $\begin{array}{l}\text { caregiver not } \\
\text { needed }\end{array}$ & $\begin{array}{l}\text { transfer to } \\
\text { wheelchair: } \\
\text { faster; } \\
\text { transfer from } \\
\text { lying to sitting: } \\
\text { similar }\end{array}$ \\
\hline Grab an object & no change & easier & no change & $\begin{array}{l}\text { not } \\
\text { performed }\end{array}$ & $\begin{array}{l}\text { not } \\
\text { performed }\end{array}$ & $\begin{array}{l}\text { not } \\
\text { performed }\end{array}$ \\
\hline $\begin{array}{l}\text { Modified Ashworth } \\
\text { exploration }\end{array}$ & $\begin{array}{l}\text { less spasticity, } \\
\text { slightly easier } \\
\text { mobilization }\end{array}$ & $\begin{array}{l}\text { less spasticity } \\
\text { overall }\end{array}$ & $\begin{array}{l}\text { less spasticity; left } \\
\text { foot improved } \\
\text { from sustained to } \\
\text { nonsustained clonus }\end{array}$ & $\begin{array}{l}\text { slight } \\
\text { improvement }\end{array}$ & $\begin{array}{l}\text { less rigidity in } \\
\text { lower limbs }\end{array}$ & no change \\
\hline Gait & no data & more stable & no data & $\begin{array}{l}\text { increased } \\
\text { velocity }\end{array}$ & $\begin{array}{l}\text { slightly } \\
\text { increased } \\
\text { velocity }\end{array}$ & no data \\
\hline Writing & no data & no change & no data & no data & no data & no data \\
\hline Joint flexibility & no data & no data & no data & $\begin{array}{l}\text { knees more } \\
\text { flexible during } \\
\text { walking }\end{array}$ & $\begin{array}{l}\text { waist more } \\
\text { flexible }\end{array}$ & no data \\
\hline Miscellaneous & no data & no data & no data & no data & $\begin{array}{l}\text { lying down } \\
\text { easier }\end{array}$ & no data \\
\hline
\end{tabular}

9-HPT, 9-Hole Peg Test; TUG, Timed Up and Go; GUG, Get Up and Go. 